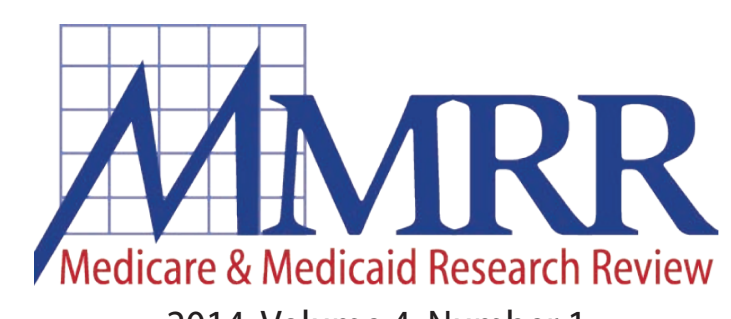

2014: Volume 4, Number 1

A publication of the Centers for Medicare \& Medicaid Services, Office of Information Products \& Data Analytics

\title{
The Impact of Medicaid Peer Support Utilization on Cost
}

\author{
Glenn Landers and Mei Zhou \\ Georgia State University-Georgia Health Policy Center
}

Background: Peer support programs have proliferated over the past decade, building on recovery oriented programming, yet relationships between peer support services and the costs to public programs have not been well described in literature. The purpose of this study is to fill gaps in the literature related to peer support programs and cost: lack of comparison groups, small sample sizes, and the availability of research examining utilization of Medicaid mental health services.

Methods: The study employed a retrospective design with treatment and comparison groups created from three administrative databases. Three ordinary least squares regression models were constructed to predict crisis stabilization cost, psychiatric hospitalization cost, and total Medicaid cost while controlling for other factors. The Chronic Illness and Disability Payment System + Rx was used to control for illness severity.

Results: Peer support was associated with $\$ 5,991$ higher total Medicaid cost $(\mathrm{p}<.01)$. Peer support was also associated with higher crisis stabilization cost and lower psychiatric hospitalization cost, but the relationships were not statistically significant. Peer support was associated with $\$ 2,100$ higher prescription drug cost $(\mathrm{p}<.01), \$ 5,116$ higher professional services cost $(p<.01)$, and $\$ 1,225$ lower facility cost $(\mathrm{p}<.01)$.

Conclusions: While the implementation of Medicaid financed peer support programs may not result in savings from reductions of costly crisis stabilizations and psychiatric hospitalizations, it does support the principles of self-direction and recovery from severe mental illness. State policy makers must weigh the potential higher cost associated with peer support programs with efforts to redesign the delivery of mental health services.

Keywords: health care costs, Medicaid, mental health

ISSN: 2159-0354

doi: http://dx.doi.org/10.5600/mmrr.004.01.a04 


\section{Medicare \& Medicaid Research Review} 2014: Volume 4, Number 1

\section{Mission Statement}

Medicare \& Medicaid Research Review is a peerreviewed, online journal reporting data and research that informs current and future directions of the Medicare, Medicaid, and Children's Health Insurance programs. The journal seeks to examine and evaluate health care coverage, quality and access to care for beneficiaries, and payment for health services.

\section{http://www.cms.gov/MMRR/}

\section{U.S. Department of Health \& Human Services Kathleen Sebelius Secretary}

\section{Centers for Medicare \& Medicaid Services Marilyn Tavenner Administrator}

Editor-in-Chief

David M. Bott, Ph.D.

The complete list of Editorial Staff and Editorial Board members may be found on the MMRR Web site (click link): $\underline{\text { MMRR Editorial Staff Page }}$

Contact: $\underline{\text { mmrr-editors@cms.hhs.gov }}$

Published by the Centers for Medicare \& Medicaid Services.

All material in the Medicare \& Medicaid Research

Review is in the public domain and may be duplicated without permission. Citation to source is requested.

\section{Introduction}

Peer support programs-services consisting of social, emotional, and instrumental support, delivered in the community by persons having a mental health condition to others sharing a similar mental health condition, to bring about a desired social or personal change (Gartner \& Riessman, 1982; Solomon, 2004)-have proliferated over the past decade (Davidson, Chinman, Sells, \& Rowe, 2006), supported by the President's New Freedom Commission recommendation that the principle of recovery should guide the U.S. mental health system (DHHS, 2003). Prior research shows that consumer delivered services, of which peer support services are a subtype, are associated with that support recovery from mental illness. Studies associate consumer delivered services with declines in symptoms and concomitant treatments (Galanter, 1988), avoidance of crisis services and inpatient admissions (Trainor \& Shepherd, 1997), higher scores of community integration and quality of life (Nelson et al., 2007), and longer community tenure (Min, Whitecraft, Rothbard, \& Salzer, 2007). Studies that directly examine the relationships among peer support, psychiatric hospitalization, and crisis intervention episodes, with exceptions (Clarke et al., 2000), report greater gains in quality of life and reductions in the number of life problems experienced (Felton et al., 1995), reductions in crisis events and hospitalizations (Klein, 1998; Landers \& Zhou, 2011), and reductions in rehospitalizations (Min et al., 2007).

The literature also indicates why consumer delivered mental health services may have implications for public payers: Medicaid's share of total U.S. mental health spending was 27 percent in 2005 (Mark, Levit, Vandivort-Warren, Buck, \& Coffey, 2011) and Medicaid reimbursement 
has facilitated the transition from institutional to community care in recent years (Walker \& Osterhaus, 2010). However, knowledge on the relationship between peer support and the cost to public programs is just emerging. Barton et al. found that psychosocial rehabilitation (including peer support) within community support systems resulted in cost savings compared to traditional hospitalization (Barton, 1999). Two recent studies of peer support suggest that it may reduce utilization of expensive inpatient services (Landers \& Zhou, 2011; Min et al., 2007). Another found that minimally guided peer support groups did not affect overall healthcare expenses (Stant et al., 2009).

The purpose of this study was to fill gaps in the literature related to peer support programs and cost: lack of comparison groups, small sample sizes (Forchuk, Martin, Chan, \& Jensen, 2005), and the availability of research examining mental health utilization paid for by Medicaid (Mark et al., 2011). This study extends the author's previous analysis of the Georgia peer support program by examining the relationships between the utilization of peer support services and cost. In light of a 2007 letter from the Centers for Medicare \& Medicaid Services providing policy guidance to state Medicaid directors for the development of Medicaid billable peer support services (Smith, 2007), and the likelihood that peer support programs will continue to expand, it is important, from a public payer perspective, to know if the utilization of peer support services is associated with lower psychiatric inpatient cost and overall Medicaid cost.

\section{Methods}

\section{Setting}

Services for individuals with serious and persistent mental illness are managed in Georgia by the Department of Behavioral Health and Developmental Disabilities (DBHDD) $)^{1}$ and financed with state and federal funds dually administered by DBHDD and the state's Medicaid program. Services are delivered within five state regions by 25 Community Services Boards. At the time of this study, psychiatric hospital services were available in seven state facilities across the five regions, and crisis stabilization services were delivered through contracted providers on a feefor-service basis. Both were supported directly with state and federal DBHDD funds.

The Georgia Peer Support Program was developed in 1999 by DBHDD as part of its emphasis on recovery oriented programming. Services are delivered statewide by Certified Peer Support Specialists. Participants must be referred to a peer support program by a licensed practitioner, elect to receive the service, and must have a primary mental health issue. Services are authorized initially for a six-month period during which an individual can receive up to 6.5 hours of service in the community per day and up to 900 hours of service in the six-month period. Services are delivered according to an individualized plan, may be delivered one-on-one or in group settings, and consist of activities that promote self-directed recovery. The focus of services must be skill maintenance and enhancement, and building consumers' capacity to advocate for themselves and other consumers (Georgia Mental Health Gap Analysis, 2009). In 2001, Georgia was the first state to implement peer support as a Medicaid billable service under the Medicaid Rehabilitation Option.

\footnotetext{
${ }^{1}$ Until reorganization in 2009, the Department was known as the Georgia Department of Human Resources, Division of Mental Health, Developmental Disabilities, and Addictive Diseases. It will
} be referred to henceforth as DBHDD. 


\section{Data}

Three data sources were used for this study. Study subjects' Medicaid eligibility status, demographic information, and non-psychiatric facility, professional, and prescription drug claims were obtained from 2003 and 2004 Georgia Medicaid data. Psychiatric hospitalization administrative and cost data from 2003 and 2004 were obtained from the Georgia DBHDD Hospital Information System. Crisis stabilization administrative and cost data from 2003 and 2004 were obtained from the same department's Community Information System. All costs are presented in 2003 dollars.

\section{Subjects}

The study employed a retrospective design with treatment and comparison groups. Waiver of consent was approved by the Georgia State University Institutional Review Board. The three databases were linked using the subject's Social Security number. As the study was designed from the perspective of Medicaid as payer, individuals were first identified in the Medicaid claims data. Subjects age 18 and older with at least one community mental health claim $^{2}$ in calendar year $2003(\mathrm{~N}=35,668)$ were identified using the Medicaid community mental health category of service code. This service code identifies all Medicaid financed community mental health service claims-including peer support claims. The data were divided into two groups: those individuals with a peer support service claim $(\mathrm{N}=1,910)$ in calendar year 2003 and those without $(\mathrm{N}=33,758)$.

The group with peer support service claims was established as the treatment group. A comparison group $(n=3,820)$ was created by using the frequency matching procedure to randomly

${ }^{2}$ Community mental health in this context is a specific Georgia Medicaid category of service code and is synonymous with an outpatient behavioral health claim. sample the group without peer support service claims in a 2:1 ratio on five matching variables: primary diagnosis, gender, race, age group, and urban/rural residence. The choice of these variables was based on a previous, small study in Missouri. That study found those who used peer support services were more likely to be female, White, older, and more likely to live in urban areas (Hodges, 2007); however, the Missouri study was not restricted to Medicaid financed peer support services. This study only analyzed the claims of Medicaid members. Frequency matching is one method to mitigate differences between the study and comparison groups in the absence of randomization (Baker \& Curbow, 1991; Clement \& Wan, 2002; Kalton \& Piesse, 2007). Data availability prohibited more sophisticated difference in differences or other analysis. Cohort demographics before and after matching are presented in Exhibit 1. Prior to matching, the treatment group was more likely than the comparison group to have a diagnosis of a schizophrenic disorder, to be male, non-White, and live in a rural area. The average age of the treatment group was 45 versus 40 for those without peer support claims. After matching, there were no statistically significant differences between the treatment and comparison groups.

The Medicaid data were then merged with the two DBHDD databases to capture psychiatric hospitalization and crisis stabilization claims incurred by each subject in calendar years 2003 and 2004. To ensure psychiatric hospital and crisis stabilization claims were incurred after the first community mental health service claim in 2003, claims with dates earlier than the first community mental health service claim in 2003 were excluded. This resulted in 14 and 13 percent of hospital claims, respectively, being excluded for the treatment and comparison groups and 19 and 11 percent of crisis stabilization claims, respectively, being excluded for the treatment and comparison groups. The 
Exhibit 1. Cohort Demographics Before and After Matching

\begin{tabular}{|c|c|c|c|c|c|c|}
\hline & \multicolumn{4}{|c|}{ Before Matching } & \multirow{2}{*}{\multicolumn{2}{|c|}{$\begin{array}{l}\text { After Matching } \\
\text { Comparison }(\mathbf{n}=)\end{array}$}} \\
\hline & \multicolumn{2}{|c|}{ Treatment } & \multicolumn{2}{|c|}{ Comparison } & & \\
\hline & $\mathbf{N}$ & Percent & $\mathbf{N}$ & Percent & $\mathbf{N}$ & Percent \\
\hline TOTAL & 1,910 & 100 & 33,758 & 100 & 3,820 & 100 \\
\hline \multicolumn{7}{|l|}{ Gender } \\
\hline Female & 1,040 & 54 & 23,288 & $69^{* * *}$ & 2,080 & 54 \\
\hline Male & 870 & 46 & 10,470 & $31^{* * *}$ & 1,740 & 46 \\
\hline \multicolumn{7}{|l|}{ Race } \\
\hline White & 821 & 43 & 15,836 & $47^{* * *}$ & 1,642 & 43 \\
\hline Non-White & 907 & 47 & 15,547 & $46^{\star * *}$ & 1,814 & 47 \\
\hline Missing & 182 & 10 & 2,375 & $7^{* * *}$ & 364 & 10 \\
\hline \multicolumn{7}{|l|}{ Age Group } \\
\hline $18-44$ & 967 & 51 & 21,880 & $65^{* * *}$ & 1,934 & 51 \\
\hline $45-64$ & 827 & 43 & 10,575 & $31^{* * *}$ & 1,654 & 43 \\
\hline $65+$ & 116 & 6 & 1,303 & $4^{\star * *}$ & 232 & 6 \\
\hline \multicolumn{7}{|l|}{ Residence Status } \\
\hline Rural & 1,001 & 52 & 15,456 & $46^{* * *}$ & 2,002 & 52 \\
\hline Urban & 909 & 48 & 18,302 & $54^{* * *}$ & 1,818 & 48 \\
\hline \multicolumn{7}{|l|}{ Age } \\
\hline Mean & 45 & - & $40^{* * *}$ & - & 44 & - \\
\hline Median & 44 & - & 39 & - & 44 & - \\
\hline \multicolumn{7}{|l|}{ Principle Diagnosis } \\
\hline Schizophrenic disorders (295) & 1,218 & 64 & 8,239 & $25^{* * *}$ & 2,436 & 64 \\
\hline Affective psychoses (296) & 444 & 23 & 10,700 & $32^{* * *}$ & 888 & 23 \\
\hline All other & 248 & 13 & 14,819 & $43^{* * *}$ & 496 & 13 \\
\hline
\end{tabular}

NOTE: ${ }^{* * *} \mathrm{p}<.01$

SOURCE: Authors' analysis.

difference in the percentage of crisis stabilization claims between groups may not be surprising given the high proportion of peer support users with a diagnosis of schizophrenic disorders.

\section{Regression Models}

Three OLS models were constructed to estimate crisis stabilization cost, psychiatric hospitalization cost, and total Medicaid cost while controlling for other factors. The models' three dependent variables were as follows: Crisis stabilization cost was the total non-Medicaid cost for short-term mental health treatment based on a per-diem.
Psychiatric hospitalization cost was the total non-Medicaid inpatient treatment cost based on a per-diem. Medicaid cost was the total Medicaid cost for all services incurred over the study period including facility (non-psychiatric inpatient), outpatient/professional (inclusive of community mental health and peer support services), and prescription drug claims. A dummy variable was used to indicate utilization of peer support services. A continuous age variable was included to further control for an individual's specific age. A dummy variable for a substance abuse diagnosis was added as a proxy for dual diagnosis (Gilmer et al., 
2009; Macias et al., 2006), because substance abuse is known to complicate the treatment of severe mental health conditions (Dickey, Fisher, Siegel, Altaffer, \& Azeni, 1997). The total number of months a beneficiary was enrolled in Medicaid during the study period was included to account for the increased opportunity an individual has to accumulate cost as the number of enrollment months per member increases (Clark, Samnaliev, \& McGovern, 2009; Thomas et al., 2005).

The Chronic Illness and Disability Payment System + Rx (CDPS+Rx) was used to control for illness severity. The CDPS was originally developed for state Medicaid departments to better adjust payments for beneficiaries with disabilities (Kronick, Gilmer, Dreyfus, \& Lee, 2000). The system is based on demographic information and more than 15,000 ICD-9 codes. There are three potential advantages of using the CDPS $+\mathrm{Rx}$ over other risk adjustment systems to account for differences in severity of illness in this population. First, it was developed specifically for Medicaid populations, and particular emphasis is placed on classifying mental health and substance abuse disorders. Second, separate scores are created for Temporary Assistance to Needy Families (TANF) and Supplemental Security Income (SSI) populations. The TANF population typically includes pregnant women and children, and the SSI population includes older adults and individuals with disabilities. Third, the CDPS can distinguish between children and adults (Weir, Aweh, \& Clark, 2008). The model's output is a risk score that is included in the multivariate models.

In 2009, the CDPS was updated to include pharmacy data, thus creating the CDPS+Rx. The inclusion of pharmacy data increases the likelihood of identifying individuals with specific pharmacy data for which there is no corresponding diagnosis and for individuals with diagnoses without expected, corresponding pharmacy utilization (Kronick, Bella, \& Gilmer, 2009). The CDPS has been validated in the literature as both a predictor of chronic illness (Weir et al., 2008) and as a measure of co-morbidity and health status (Clark et al., 2009; Gilmer et al., 2009; Macias et al., 2006; Thomas et al., 2005). Because the study's population was Medicaid SSI adults, the CDPS $+\mathrm{Rx}$ was an appropriate risk adjuster.

\section{Results}

The descriptive results are presented in Exhibit 2. Those in the treatment group - with peer supporthad fewer psychiatric hospital admissions on average (1.35 vs. 1.58) and more episodes of crisis stabilization (1.09 vs. .84$)$ than those in the comparison group, although only the crisis stabilization results were statistically significant. The average length of stay for psychiatric hospitalization was slightly lower for the study group (19.2 vs. 21.5), but the average length of stay for crisis stabilization was slightly higher (7.2 vs. 6.1). Neither result was statistically significant. There were no significant differences in average number of months in Medicaid over the study period. Costs for psychiatric hospitalization and crisis stabilization were not significantly different between groups, but all Medicaid costs-total cost, facility cost, professional cost, and prescription drug cost-were significantly higher for the treatment group. Within the treatment group, the mean number of peer support claims per subject was 125 , the median 79 , and the range 1 to 530 .

The model results are presented in Exhibit 3. Peer support was associated with $\$ 5,990.87$ higher total Medicaid cost $(\mathrm{p}<.01)$. Peer support was also associated with higher crisis stabilization cost and lower psychiatric hospitalization cost, but the relationships were not statistically significant. 
Exhibit 2. Descriptive Results

\begin{tabular}{|c|c|c|}
\hline & $\begin{array}{l}\text { Treatment } \\
(\mathrm{N}=1,910)\end{array}$ & $\begin{array}{c}\text { Comparison } \\
(\mathrm{N}=3,820)\end{array}$ \\
\hline \multicolumn{3}{|l|}{ Average Utilization } \\
\hline Psychiatric hospital admissions & 1.35 & 1.58 \\
\hline Crisis stabilization episodes & 1.09 & $0.84^{\star *}$ \\
\hline \multicolumn{3}{|l|}{ Average Length of Stay } \\
\hline Psychiatric hospital & 19.2 & 21.5 \\
\hline Crisis stabilization & 7.2 & 6.1 \\
\hline \multicolumn{3}{|l|}{ Average Cost } \\
\hline Psychiatric hospital & $\$ 16,454$ & $\$ 18,595$ \\
\hline Crisis stabilization & $\$ 2,405$ & $\$ 2,401$ \\
\hline Total Medicaid & $\$ 27,904$ & $\$ 19,926^{\star * *}$ \\
\hline Facility & $\$ 3,634$ & $\$ 4,426^{\star *}$ \\
\hline Professional & $\$ 13,408$ & $\$ 7,563^{\star * *}$ \\
\hline Peer Support & $\$ 4,550$ & $\mathrm{~N} / \mathrm{A}$ \\
\hline $\mathrm{Rx}$ & $\$ 10,861$ & $\$ 7,937^{* * *}$ \\
\hline Average months of Medicaid enrollment & 22.9 & 21.7 \\
\hline
\end{tabular}

NOTE: ${ }^{* *} p<.01,{ }^{* * *} p<.001$

SOURCE: Authors' analysis.

Exhibit 3. Relationships among Peer Support and Crisis Stabilization Cost, Psychiatric Hospitalization Cost, and Total Medicaid Cost $(\mathrm{N}=5,730)$

\begin{tabular}{|c|c|c|c|c|c|c|}
\hline & $\begin{array}{c}\text { Crisis } \\
\text { Stabilization } \\
\text { Cost }^{\mathrm{a}}(\$) \\
\end{array}$ & SE & $\begin{array}{c}\text { Psychiatric } \\
\text { Hospitalization } \\
\text { Cost }^{\mathrm{b}}(\$)\end{array}$ & SE & $\begin{array}{c}\text { Medicaid } \\
\operatorname{Cost}^{c}(\$)\end{array}$ & SE \\
\hline Peer Support & 49.54 & 26.11 & -483.62 & 426.76 & $5,990.87^{\star \star}$ & 531.10 \\
\hline Age & $-3.24^{\star *}$ & .97 & $-34.93^{*}$ & 15.81 & -27.57 & 19.68 \\
\hline Substance abuse & $282.18^{\star *}$ & 39.49 & 55.38 & 645.33 & $-1,497.52$ & 803.12 \\
\hline Length of enrollment (mos.) & -.43 & 2.73 & $-87.61^{\star}$ & 44.62 & $942.61^{\star *}$ & 55.53 \\
\hline$C D P S+R x$ score & $16.87^{\star}$ & 7.16 & $359.55^{\star *}$ & 116.96 & $5,221.88^{\star \star}$ & 145.56 \\
\hline
\end{tabular}

NOTES: ${ }^{\mathrm{a} F u l l}$ model: $\mathrm{R}^{2}=.014$, adjusted $\mathrm{R}^{2}=.013 ; \mathrm{F}=15.61, \mathrm{df}=5$ and $5,724, \mathrm{p}<.0001$

${ }^{\mathrm{b}}$ Full model: $\mathrm{R}^{2}=.003$, adjusted $\mathrm{R}^{2}=.002 ; \mathrm{F}=3.55, \mathrm{df}=5$ and $5,724, \mathrm{p}<.01$

cFull model: $\mathrm{R}^{2}=.259$, adjusted $\mathrm{R}^{2}=.259 ; \mathrm{F}=401, \mathrm{df}=5$ and $5,724, \mathrm{p}<.0001$

${ }^{*} \mathrm{p}<.05,{ }^{* *} \mathrm{p}<.01$

SOURCE: Authors' analysis.

For every year of age, crisis stabilization cost decreased \$3.24 ( $\mathrm{p}<.01)$ and psychiatric hospitalization cost decreased $\$ 34.93$ ( $\mathrm{p}<.05)$. Presence of a substance abuse diagnosis increased crisis stabilization cost $\$ 282.18(\mathrm{p}<.01)$. Each month of Medicaid enrollment decreased psychiatric hospitalization cost \$87.61 ( $\mathrm{p}<.05)$ and increased total Medicaid cost $\$ 942.61(\mathrm{p}<.01)$. Each unit increase of CDPS+Rx risk score increased crisis stabilization cost $\$ 16.87(\mathrm{p}<.05)$, psychiatric hospitalization cost $\$ 359.55(\mathrm{P}<.01)$, and total Medicaid cost $\$ 5,221.88(\mathrm{p}<.01)$. 
Because of the range in the number of peer support claims per treatment subject, additional sub-analyses were conducted with subjects with peer support claims below (low users) and above (high users) the median number of 79. Peer support in low users was associated with higher crisis stabilization cost $(\$ 148.66 ; \mathrm{p}<.01)$. However, Peer support in high users was associated with lower psychiatric hospitalization cost $(-\$ 1,480.21$; $\mathrm{p}<.01)$. Total Medicaid cost was significantly higher for both groups when compared with those without peer support claims.

To further understand the components of the higher total Medicaid cost, the total Medicaid cost model was decomposed into three models testing the relationships between peer support and facility cost, professional (outpatient) cost, and prescription drug cost. Facility cost includes acute hospitals but does not include psychiatric hospitals, as previously indicated. Professional cost includes community mental health services and peer support, among other outpatient costs. Results are presented in Exhibit 4. Peer support was associated with \$2,099.55 higher prescription drug cost, $\$ 5,115.84$ higher professional services cost $(\mathrm{p}<.01)$, and $\$ 1,224.52$ lower facility cost $(\mathrm{p}<.01)$.

\section{Discussion}

Although various outcomes related to peer support services have been described in the literature, most studies have focused on the relationships between peer support and quality of life, reductions in the number of life problems experienced (Felton et al., 1995), self-reported reductions in crisis events and hospitalizations (Klein, 1998), and reductions in rehospitalizations (Min et al., 2007) - all important outcomes. Only a few have explored cost, and those have tended to rely on self-reported data. The authors are aware of no other study that uses Medicaid administrative data to examine the association between peer support and the costs of psychiatric hospitalization, crisis stabilization, and total Medicaid costs. This study begins to fill this gap in the literature by comparing the experiences of a population of those who used peer support services within the Medicaid system with a comparison group of those who did not. The study also strengthens an observational design by first performing a frequency matching procedure to create a comparison group that is similar to the treatment group, along five diagnostic and demographic variables, and by incorporating a CDPS $+\mathrm{Rx}$ risk

Exhibit 4. Relationships among Peer Support and Medicaid Facility Cost, Professional Cost, and Prescription Drug Cost $(\mathrm{N}=5,730)$

\begin{tabular}{|c|c|c|c|c|c|c|}
\hline & Facility & & Professional & & & \\
\hline & $\operatorname{Cost}^{\mathrm{a}}(\$)$ & SE & $\operatorname{Cost}^{\mathrm{b}}(\$)$ & SE & $\operatorname{Rx} \operatorname{Cost}^{c}(\$)$ & SE \\
\hline Peer Support & $-1,224.52^{\star *}$ & 252.82 & $5,115.84^{\star *}$ & 356.78 & $2,099.55^{\star *}$ & 228.32 \\
\hline Age & -12.91 & 9.37 & $-37.18^{\star \star}$ & 13.22 & $22.52^{\star *}$ & 8.46 \\
\hline Substance abuse & 267.78 & 382.30 & -397.57 & 539.49 & $-1,367.73^{\star *}$ & 345.25 \\
\hline Length of enrollment (mos.) & -13.43 & 26.43 & $485.59^{\star *}$ & 37.30 & $470.45^{\star *}$ & 23.87 \\
\hline$C D P S+R x$ score & $2,954.88^{\star *}$ & 69.29 & $1,077.97^{\star *}$ & 97.78 & $1,189.04^{\star *}$ & 62.58 \\
\hline NOTES: a Full model: $\mathrm{R}^{2}=.255$, adju & $\mathrm{R}^{2}=.25 ; \mathrm{F}=3$ & $f=5$ and & $\mathrm{p}<.0001$ & & & \\
\hline 'bull model: $\mathrm{R}^{2}=.093$, adjusted $\mathrm{R}^{2}=$ & $093 ; \mathrm{F}=118, \mathrm{df}=$ & nd 5,724 , $\mathrm{p}$ & & & & \\
\hline 'Full model: $\mathrm{R}^{2}=.160$, adjusted $\mathrm{R}^{2}=$ & $159 ; \mathrm{F}=218, \mathrm{df}=$ & nd $5,724, \mathrm{p}$ & & & & \\
\hline${ }^{* *} \mathrm{p}<.01$ & & & & & & \\
\hline SOURCE: Authors' analysis. & & & & & & \\
\hline
\end{tabular}


score in the regression models to account for differences in illness severity between groups not accounted for in the matching process.

The most important finding for policy makers is the significantly higher total Medicaid cost for those who used peer support services. Peer support services are associated with an additional $\$ 5,991$ ( $\mathrm{p}<.01)$ in the total Medicaid cost model. This is not surprising, considering the lack of community-based services provided in Georgia in 2003. A 2005 gap analysis by APS Healthcare showed that Georgia ranked 43 nationally in percapita mental health services spending ("Georgia Mental Health Gap Analysis," 2005). It also showed that only 17 percent of adults who needed individual community support in fiscal year 2004 received it. Georgia is in the process of closing all of its state supported psychiatric hospitals and transitioning individuals to the community as a result of a 2010 settlement agreement with the Department of Justice. Peer support services are one of the supports offered to those transitioning to community settings, and these findings might be helpful to states undergoing similar system transformations. In 2012, the Governor's budget included \$35,650,039 in support for expanding community-based services and a decrease in funding for inpatient treatment (Honberg, Diehl, Kimball, Gruttadaro, \& Fitzpatrick, 2011).

Additional analyses of subjects with utilization of peer support above and below the median of 79 claims also revealed interesting findings. Those with peer support claims below the median had significantly higher crisis stabilization cost, and those with peer support claims above the median had significantly lower psychiatric hospitalization cost. Although limited, these sub-analyses may shed light on dose response and indicate the value of receiving peer support for longer periods of time.

Increased cost with the introduction of a new service might seem intuitive; however, there is a history of introducing new services, techniques, and procedures that result in overall cost savings. For example, vaccinating children and the elderly reduces or prevents costly and sometimes deadly illnesses (Nichol, Margolis, Wuorenma, \& Von Sternberg, 1994; Riddiough, Sisk, \& Bell, 1983; Salo et al., 2006; White, Lavoie, \& Nettleman, 1999). State Medicaid programs continue to expand home and community-based waiver programs as an alternative to expensive institutional care (Doty, 2000; Skellie, Mobley, \& Coan, 1982; Vertrees, Manton, \& Adler, 1989), though actual savings to the Medicaid program are inconclusive (Grabowski, 2006). In this study, we might have expected to see increases in total Medicaid cost offset by reductions in the cost of crisis stabilization and psychiatric hospitalization; however, there were no significant differences between the treatment and comparison groups.

Peer support was also a significant predictor of higher professional cost and prescription drug cost. A review of additional descriptive data revealed that those who used peer support services had, on average, 2.5 times more professional claims than those who did not use peer support services. Of the professional claims, those who used peer support services had, on average, more than three times the number of community mental health claims than those who did not use peer support services. This result is supported by Hodges (2007) who suggested those who use peer support services are likely to utilize more services of all kinds compared with those who do not use peer support, and this may result in better overall quality of care. The higher prescription drug cost appears to be driven by differences in the quantity of prescriptions between groups. Again, a review of the descriptive data showed that those who used peer support services averaged 113 prescriptions over the study period, while those who did not use peer support averaged 90 prescriptions. 
An unexpected finding from the facility cost model was that peer support was a significant predictor of lower inpatient cost, even after controlling for illness severity. In the descriptive results, there was no significant difference in number of admissions to (non-psychiatric) hospitals for acute services. Previous studies have described reduced or avoided admissions to psychiatric hospitals for individuals who used peer support services (Klein, 1998; Landers \& Zhou, 2011; Min et al., 2007; Trainor \& Shepherd, 1997), but none has reported reductions in acute inpatient costs. Additional research is warranted to understand if the benefits of peer support translate to improvements in an individual's physical as well as mental health.

The results of this study complement the many promising quality of life outcomes associated with peer support that have been described in the literature, such as overcoming stigma, securing and maintaining employment (Anthony, 1993), and improving community integration (Nelson et al., 2007) and tenure (Min et al., 2007), among others. The intention here is to raise the awareness of policy makers as to the broader budgetary implications of implementing Medicaid financed peer support programs. While the association between peer support and lower psychiatric hospitalization cost was not statistically significant, it may be practically and clinically significant.

There are several data and methodological limitations in this work. The study is observational and lacks a randomized control group, so the results can only be interpreted as associations and not causation. Data limitations precluded the use of more sophisticated difference in differences modeling. The study is also limited to individuals enrolled in one state's Medicaid program, and the study's perspective is Medicaid as payer. Although all of the subjects were eligible for Medicaid, they do not represent all peer support participants. Forty-five percent of the treatment group and 38 percent of the comparison group were dually-eligible. Therefore, this analysis reflects the costs to Medicaid and may not be generalizable to the overall population of peer support participants, including those who are dually eligible for Medicare.

The researchers attempted to improve upon previous work by utilizing frequency matching to create a comparison group based on five demographic and diagnostic variables and by including a CDPS $+\mathrm{Rx}$ risk score as a control for illness severity, including a control for substance abuse, and controlling for length of Medicaid enrollment during the study period. However, the researchers acknowledge that unmeasured bias may still be present. Because the researchers had access only to cross sectional data from calendar years 2003 and 2004, they were not able to measure activity prior to 2003. Psychiatric hospitalization and crisis stabilization claims that were incurred after January 1, 2003, but prior to the first community mental health claim in the same year, were excluded from the study. This resulted in 14 and 13 percent of hospital claims, respectively, being excluded for the treatment and comparison groups and 19 and 11 percent of crisis stabilization claims, respectively, being excluded for the treatment and comparison groups. Results before and after this exclusion were similar; however, it is possible that unmeasured history effects remain. Further, no distinction was made between low and high peer support utilization. The mean number of peer support claims per treatment subject was 125 , the median 79 , and the range 1 to 530 . For this reason, the main results should be interpreted as the average experience of individuals who access peer support services. 


\section{Conclusions and Implications for Practice}

Our results showed peer support to be associated with higher total Medicaid cost, higher Medicaid drug cost, higher Medicaid professional cost, and lower facility cost. The relationships between peer support, crisis stabilization, and psychiatric hospitalization were not significant except in the sub-analyses. While the implementation of Medicaid financed peer support programs may not result, on average, in savings from reductions of costly crisis stabilizations and psychiatric hospitalizations, it does support the principles of self-direction and recovery from severe mental illness. State policy makers must weigh the potential higher cost associated with peer support programs with efforts to redesign the delivery of mental health services and to support the principles of self-direction and recovery.

\section{Disclaimer}

The authors have been requested to report any funding sources and other affiliations that may represent a conflict of interest. The authors reported that there are no conflict of interest sources.

\section{Correspondence}

Glenn Landers, Sc.D., Georgia State UniversityGeorgia Health Policy Center, 14 Marietta St., Atlanta, Georgia 30303, glanders@gsu.edu, Tel. 4044130294

\section{Acknowledgment}

We would like to acknowledge Jon Quisenberry and Wendy Tiegreen, of the Georgia Department of Behavioral Health and Developmental Disabilities, who facilitated access to data.

\section{References}

Anthony, W. A. (1993). Recovery from mental illness: The guiding vision of the mental health service system in the 1990s. Psychosocial
Rehabilitation Journal, 16(4), 11. http://dx.doi. org/10.1037/h0095655

Baker, F., \& Curbow, B. (1991). The case-control study in health program evaluation. Evaluation and Program Planning, 14(4), 263-272. http:// dx.doi.org/10.1016/0149-7189(91)90008-5

Barton, R. (1999). Psychosocial rehabilitation services in community support systems: A review of outcomes and policy recommendations. Psychiatric Services (Washington, D.C.), 50(4), 525-534. PubMed

Clark, R. E., Samnaliev, M., \& McGovern, M. P. (2009). Impact of Substance Disorders on Medical Expenditures for Medicaid Beneficiaries With Behavioral Health Disorders. Psychiatric Services (Washington, D.C.), 60(1), 35-42. PubMed http://dx.doi.org/10.1176/appi. ps.60.1.35

Clarke, G. N., Herinckx, H. A., Kinney, R. F., Paulson, R. I., Cutler, D. L., Lewis, K., \& Oxman, E. (2000). Psychiatric Hospitalizations, Arrests, Emergency Room Visits, and Homelessness of Clients with Serious and Persistent Mental Illness: Findings from a Randomized Trial of Two ACT Programs vs. Usual Care. Mental Health Services Research, 2(3), 155-164. PubMed http://dx.doi.org/10.1023/ A:1010141826867

Clement, D., \& Wan, T. (2002). Evaluating Health Services, Programs, and Systems. Epidemiology and the Delivery of Health Care Services, 133-154.

Davidson, L., Chinman, M., Sells, D., \& Rowe, M. (2006). Peer Support Among Adults With Serious Mental Illness: A Report From the Field. Schizophrenia Bulletin, 32, 443-450. PubMed http://dx.doi.org/10.1093/schbul/sbj043 
DHHS, D. o. H. a. H. S. (2003). New Freedom Commission on Mental Health, Achieving the Promise: Transforming Mental Health Care in America. Final Report. (SMA-033832). Retrieved from http://www.nami.org/ Template.. fm ? Section $=$ Policy $\&$ Template $=/$ ContentManagement/ContentDisplay. cfm\&ContentID=16699

Dickey, B., Fisher, W., Siegel, C., Altaffer, F., \& Azeni, H. (1997). The cost and outcomes of community-based care for the seriously mentally ill. Health Services Research, 32(5), 599-614. PubMed

Doty, P. (2000). Cost-effectiveness of home and community-based long-term care services. Washington, DC: US Department of Health and Human Services.

Felton, C. J., Stastny, P., Shern, D. L., Blanch, A., Donahue, S. A., Knight, E., \& Brown, C. (1995). Consumers as peer specialists on intensive case management teams: impact on client outcomes. Psychiatric Services (Washington, D.C.), 46, 1037-1044. PubMed

Forchuk, C., Martin, M. L., Chan, Y. L., \& Jensen, E. (2005). Therapeutic relationships: from psychiatric hospital to community. Journal of Psychiatric and Mental Health Nursing, 12(5), 556-564. PubMed http://dx.doi.org/10.1111/ j.1365-2850.2005.00873.x

Galanter, M. (1988). Zealous self-help groups as adjuncts to psychiatric treatment: a study of Recovery, Inc. The American Journal of Psychiatry, 145, 1248-1253. PubMed

Gartner, A. J., \& Riessman, F. (1982). Self-help and mental health. Hospital \& Community Psychiatry, 33(8), 631-635. PubMed
Georgia Mental Health Gap Analysis (2005). In A. Healthcare (Ed.), (pp. 345). Atlanta: APS Healthcare.

Georgia, S. o. (2009). Provider Manual for Community Mental Health, Developmental Disabilities and Addictive Diseases Providers. State of Georgia Retrieved from http://dbhdd. org/files/Provider-Manual-BH.pdf

Gilmer, T. P., Ojeda, V. D., Barrio, C., Fuentes, D., Garcia, P., Lanouette, N. M., \& Lee, K. C. (2009). Adherence to Antipsychotics Among Latinos and Asians With Schizophrenia and Limited English Proficiency. Psychiatric Services (Washington, D.C.), 60(2), 175-182. PubMed http://dx.doi.org/10.1176/appi.ps.60.2.175

Grabowski, D. C. (2006). The Cost-Effectiveness of Noninstitutional Long-Term Care Services: ReviewandSynthesisoftheMostRecentEvidence. Medical Care Research and Review, 63(1), 3-28. http://dx.doi.org/10.1177/1077558705283120 PubMed

Hodges, J. Q. (2007). Peer Support Among Consumers of Professional Mental Health Services: Implications for Practice, Policy, and Research. Journal of Human Behavior in the Social Environment, 14(3), 81-92. http://dx.doi. org/10.1300/J137v14n03_04

Honberg, R., Diehl, S., Kimball, A., Gruttadaro, D., \& Fitzpatrick, M. (2011). State Mental Health Cuts: A National Crisis (pp. 22). Arlington.

Kalton, G., \& Piesse, A. (2007). Survey research methods in evaluation and case-control studies. Statistics in Medicine, 26(8), 1675-1687. PubMed http://dx.doi.org/10.1002/ $\operatorname{sim} .2796$

Klein, A. R. (1998). Significance of Peer Social Support With Dually Diagnosed Clients: 
Findings From a Pilot Study. Research on Social Work Practice, 8(5), 529. http://dx.doi. org/10.1177/104973159800800503

Kronick, R., Bella, M., \& Gilmer, T. (2009). The Faces of Medicaid III: Refining the Portrait of People with Multiple Chronic Conditions. In L. Martin (Ed.), The Faces of Medicaid (pp. 30): Center for Health Care Strategies, Inc.

Kronick, R., Gilmer, T., Dreyfus, T., \& Lee, L. (2000). Improving health-based payment for Medicaid beneficiaries: CDPS. [Article]. Health Care Financing Review, 21(3), 29-64. PubMed

Landers, G. M., \& Zhou, M. (2011). An Analysis of Relationships Among Peer Support, Psychiatric Hospitalization, and Crisis Stabilization. Community Mental Health Journal, 47(1), 106-112. http://dx.doi.org/10.1007/s10597-0099218-3 PubMed

Macias, C., Rodican, C. F., Hargreaves, W. A., Jones, D. R., Barreira, P. J., \& Wang, Q. (2006). Supported employment outcomes of a randomized controlled trial of ACT and clubhouse models. [Article]. Psychiatric Services (Washington, D.C.), 57(10), 1406-1415. PubMed http://dx.doi.org/10.1176/appi.ps.57.10.1406

Mark, T. L., Levit, K. R., Vandivort-Warren, R., Buck, J. A., \& Coffey, R. M. (2011). Changes In US Spending On Mental Health And Substance Abuse Treatment, 1986-2005, And Implications For Policy. Health Affairs, 30(2), 284-292. http:// dx.doi.org/10.1377/hlthaff.2010.0765 PubMed

Min, S.-Y., Whitecraft, J., Rothbard, A. B., \& Salzer, M. S. (2007). Peer Support for Persons with CoOccurring Disorders and Community Tenure: A Survival Analysis. Psychiatric Rehabilitation Journal, 30(3), 207-213. PubMed http://dx.doi. org/10.2975/30.3.2007.207.213
Nelson, G., Ochocka, J., Janzen, R., Trainor, J., Goering, P., \& Lomotey, J. (2007). A longitudinal study of mental health consumer/ survivor initiatives: Part V: Outcomes at 3-year follow-up. Journal of Community Psychology, 35(5), 655-665. http://dx.doi.org/10.1002/ jcop.20171

Nichol, K. L., Margolis, K. L., Wuorenma, J., \& Von Sternberg, T. (1994). The Efficacy and Cost Effectiveness of Vaccination against Influenza among Elderly Persons Living in the Community. The New England Journal of Medicine, 331(12), 778-784. http://dx.doi.org/10.1056/ NEJM199409223311206 PubMed

Riddiough, M. A., Sisk, J. E., \& Bell, J. C. (1983). Influenza Vaccination: Cost-effectiveness and Public Policy. Journal of the American Medical Association, 249(23), 3189-3195. http://dx.doi. org/10.1001/jama.1983.03330470029026 PubMed

Salo, H., Kilpi, T., Sintonen, H., Linna, M., Peltola, V., \& Heikkinen, T. (2006). Cost-effectiveness of influenza vaccination of healthy children. Vaccine, 24(23), 4934-4941. http://dx.doi. org/10.1016/j.vaccine.2006.03.057 PubMed

Skellie, F. A., Mobley, G. M., \& Coan, R. E. (1982). Cost-effectiveness of community-based long-term care: current findings of Georgia's alternative health services project. American Journal of Public Health, 72(4), 353-358. http:// dx.doi.org/10.2105/AJPH.72.4.353 PubMed

Smith, D. (2007). State Medicaid Directors Letter \#07-11.(SMDL\#07-011). Centers for Medicare \& Medicaid Services, Center for Medicaid and State Operations Retrieved from http://downloads. cms.gov/cmsgov/archived-downloads/SMDL/ downloads/SMD081507A.pdf 
Solomon, P. (2004). Peer support/peer provided services underlying processes, benefits, and critical ingredients. Psychiatric Rehabilitation Journal, 27(4), 392-401. PubMed http://dx.doi. org/10.2975/27.2004.392.401

Stant, A. D., Castelein, S., Bruggeman, R., van Busschbach, J. T., van der Gaag, M., Knegtering, H., \& Wiersma, D. (2009). Economic Aspects of Peer Support Groups for Psychosis. Community Mental Health Journal; Epub ahead of print. PubMed

Thomas, M. R., Waxmonsky, J. A., Gabow, P. A., Flanders-McGinnis, G., Socherman, R., \& Rost, K. (2005). Prevalence of psychiatric disorders and costs of care among adult enrollees in a Medicaid HMO. [Article]. Psychiatric Services (Washington, D.C.), 56(11), 1394-1401. PubMed http://dx.doi.org/10.1176/appi.ps.56.11.1394

Trainor, J., \& Shepherd, M. (1997). Beyond the service paradigm: The impact and implications of consumerinitiatives. Psychiatric Rehabilitation
Journal, 21(2), 132. http://dx.doi.org/10.1037/ h0095328

Vertrees, J. C., Manton, K., \& Adler, G. (1989). Cost effectiveness of home and community-based care. Health Care Financing Review, 10(4), 65. PubMed

Walker, M. A., \& Osterhaus, J. (2010). Medicaid fee for service reimbursement and the delivery of human services for individuals with developmental disabilities or severe mental illness: negotiating cost. Journal of Health and Human Services Administration, 32(4), 380-404. PubMed

Weir, S., Aweh, G., \& Clark, R. E. (2008). Case Selection for a Medicaid Chronic Care Management Program. [Article]. Health Care Financing Review, 30(1), 61-74. PubMed

White, T., Lavoie, S., \& Nettleman, M. D. (1999). Potential Cost Savings Attributable to Influenza Vaccination of School-aged Children. Pediatrics, 103(6), e73. 